\title{
Histo-morphology of genitalia in crossbred dairy cows with kinked cervix
}

\author{
V.R. Annie' ${ }^{1}$, K.M. Lucy², N. Ashok ${ }^{3}$, S. Maya ${ }^{4}$, \\ M.H. Hiron ${ }^{5}$ and T. Sathu ${ }^{6}$ \\ Department of Veterinary Anatomy and Histology \\ College of Veterinary and Animal Sciences, Mannuthy, Thrissur, Kerala, 680651. \\ Kerala Veterinary and Animal Sciences University, India.
}

Citation: Annie, V.R., Lucy, K.M., Ashok, N., Maya, S., Hiron, M.H. and Sathu, T. 2021. Histo-morphology of genitalia in crossbred dairy cows with kinked cervix. J. Vet. Anim. Sci. 52(2): 191-195. DOI: https://doi.org/10.51966/jvas.2021.52.2.191-195

Received: 08.01.2021

Accepted: 07.02.2021

Published: 01.06.2021

\section{Abstract}

The study was conducted on genitalia collected from 100 dairy cows/heifers from the Meat Technology Unit, Mannuthy. The animals brought for slaughter at Meat Technology Unit, Mannuthy were from herds of five different farms (University and Government Undertaking farms) in Kerala state. This included six animals culled on account of factors other than infertility with normal reproductive system (control group) and the remaining animals with a known history of infertility. In total, seven animals showed kinked cervix condition. Cervix was evaluated morphometrically and histologically. Grossly, the cervix was hard, kinked and S-shaped, with a mean length of 9.64 $\pm 1.19 \mathrm{~cm}$. Average number of annular rings in the cervical canal was $4.14 \pm 0.26$ with an average diameter of $1.74 \pm 0.18 \mathrm{~cm}$. At the external os, diameter of the cervix was less, while at the uterine end, diameter was more. The opening of each cervical ring showed a misalignment instead of a straight line. Histologically, the cervix was lined by simple columnar epithelium with signs of degeneration and desquamation. However, the submucosal layer was extensively infiltrated by collagen fibres. In uterus, there was a significant difference in the number of endometrial glands and height of the glandular epithelial cells which was less when compared to the control group. Muscular layer outer to connective tissue layer was thin and uneven. Alterations of the glandular structures negatively influence the viability of spermatozoa due to the lack of secretory products. This fibrous, collagen rich kinked cervix limits the smooth deposition of the semen into the uterus during artificial insemination and the insufficiently dilated cervix affects its contractibility leading to dystocia and subfertility.

Key Words: Kinked cervix, Histomorphology, Dairy cows

Regular and successful reproduction is the key for profitable cattle production. The

${ }^{*}$ Part of PhD thesis submitted to Kerala Veterinary and Animal Sciences University,

Pookode, Wayanad, Kerala

1. PhD Scholar

2. Professor and Controller of Examinations, Directorate of Academics and Research, KVASU

Corresponding author: Ph: 9446408861 email id: lucy@kvasu.ac.in

3. Registrar, KVASU

4. Professor and Head

5. Assistant Professor, Department of Animal Reproduction Gynaecology and Obstetrics

6. Assistant Professor, Department of Livestock Products Technology

Copyright: (c) 2021 V.R. Annie et al. This is an open access article distributed under the terms of the Creative Commons Attribution 4.0 International License (http://creativecommons.org/licenses/by/4.0/), which permits unrestricted use, distribution, and reproduction in any medium, provided the original author and source are credited. 
reproductive performance depends upon the normal structure and function of the genitalia. Any structural and functional abnormalities in the reproductive system may interrupt reproductive efficiency. Mullerian ducts are the primordia for development of internal reproductive tracts in females and differentiate into fallopian tubes, uterus, cervix and upper part of the vagina (Kaufman and Bard, 1999). Cervix is a selfcontained organ in the reproductive tract, which represents the anatomical and functional barrier between the vagina and the uterus. The knowledge of biometrical status of cervix is essential to perform artificial insemination and while dealing with infertility problems. Kinked cervix is one of the known inherited causes of infertility in dairy cattle in which the cervix region will be in the form of S-shaped structure (Jagir et al., 2009). Collagen is one of the most important components that give rigidity to the cervix and its content changes significantly according to the physiological status of the animal. Reliable information on the parameters of anatomical abnormality of cervix in crossbred dairy cows is scanty. Hence, the present study was designed to explore the morphological, histological and histochemical aspects of genitalia with kinked cervix in crossbred cattle.

The present study was conducted on the female genitalia collected from 100 dairy cows/heifers from the Meat Technology Unit, Mannuthy. The animals brought for slaughter at Meat Technology Unit, Mannuthy were from herds of five different farms (University and Government Undertaking farms) in Kerala state. This included six animals culled on account of factors other than infertility (like wart, abscess, laminitis etc) with normal reproductive system (control group) and the remaining animals with a known history of infertility. In total, seven animals showed kinked cervix condition. Morphology and morphometry of various parts of the genitalia viz., ovary, oviduct, horns, body of the uterus and cervix were noted. Morphometric measurements were recorded with the help of Vernier Calipers and non-stretchable thread. The patency of the oviduct was assessed through the perfusion of 0.9 per cent sodium chloride solution with 1 per cent methylene blue. Methylene blue stained the entire passage of oviduct during its course through the genital tract. Tissue samples from different regions were fixed in 10 per cent neutral buffered formalin. Standard procedures were adopted for histoarchitectural and histochemical studies. Histologically in the cervix H\&E, Masson's trichrome stain and Verhoeff's elastic stain were employed (Luna, 1968). Histochemically, presence of carbohydrates, mucin, phosphates and lipids were demonstrated by Mc Manus method, per iodic acid - alcian blue stain, Gomori's method and osmium tetroxide stains. The micrometrical parameters like thickness of each layer of ovary, oviduct, uterine horn, body of uterus and cervix were measured using Leica Application Suite software. The parameters of normal and anatomically defective samples were compared statistically.

Among the 100 female genitalia collected, cervical abnormality was the most common type found, giving an estimated incidence of seven per cent. Animals were in good physical condition with no defects of the external genitalia. On gross examination, genital structures were observed as normal except the cervix. In all cases, cervix was very hard, twisted and bent in the form S-shaped structure (Fig. 1).

Average measurements of the left ovary viz. length, width and thickness were recorded as $3.23 \pm 0.18 \mathrm{~cm}, 2.24 \pm 0.27 \mathrm{~cm}$ and $1.56 \pm 0.21 \mathrm{~cm}$, respectively and that of the right ovary were $3.68 \pm 0.29 \mathrm{~cm}, 2.27 \pm 0.19$ $\mathrm{cm}$ and $1.90 \pm 0.12 \mathrm{~cm}$, respectively. The mean weight of left and right ovaries was $7.94 \pm 1.06$ $\mathrm{g}$ and $8.94 \pm 1.14 \mathrm{~g}$, respectively. The ovaries were rounded to oval in shape and functionally active with follicular structures of various sizes. The left and right oviducts were torturous, wavy, attached with mesosalpinx and opened at the fimbria. In one genitalia, left oviduct showed a tubal obstruction near to utero-tubal junction. The left and right oviducts had an average length of $26.07 \pm 0.98 \mathrm{~cm}$ and $27.21 \pm 0.90$ $\mathrm{cm}$, respectively. Mean length of left uterine horns was measured as $31.64 \pm 1.77 \mathrm{~cm}$ and thickness as $0.27 \pm 0.02 \mathrm{~cm}$. Right uterine horn was having a length of $30.50 \pm 1.62 \mathrm{~cm}$ and thickness of $0.30 \pm 0.02 \mathrm{~cm}$. Body of the uterus was $3.29 \pm 0.26 \mathrm{~cm}$ long with a thickness of $0.34 \pm 0.03 \mathrm{~cm}$. 
Fig. 1. External appearance of genitalia

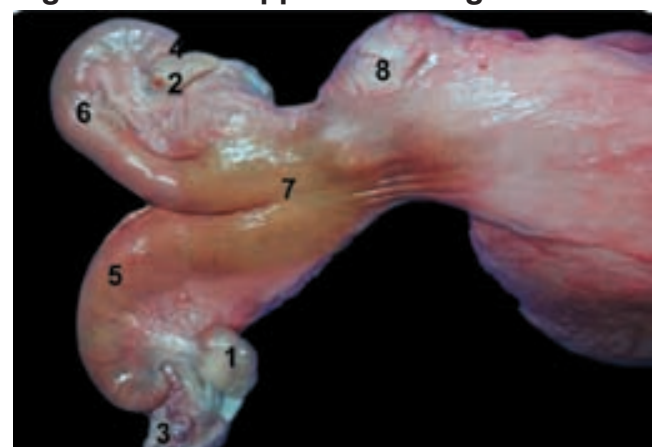

1. Left ovary, 2. Right ovary, 3. Left oviduct 4. Right oviduct, 5. Left uterine horn 6. Right uterine horn, 7. Body of uterus 8. Cervix

Fig. 2. Bent cervical lumen in kinked cervix

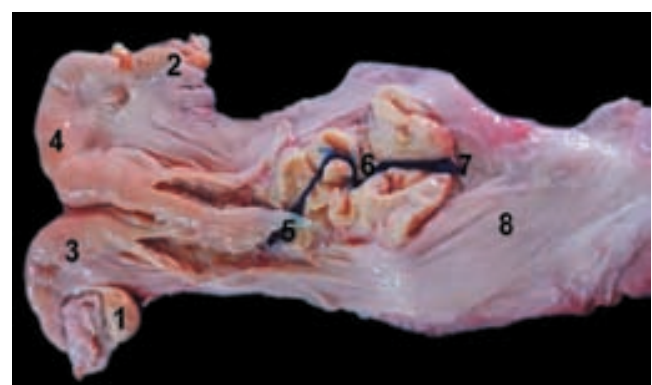

1. Left ovary 2. Right ovary,

3. Left uterine horn, 4. Right uterine horn

5. Internal orifice, 6. Cervical canal

7. External orifice, 8. Vagina

Fig. 3. Cross section of ovary. H\&E. x 100

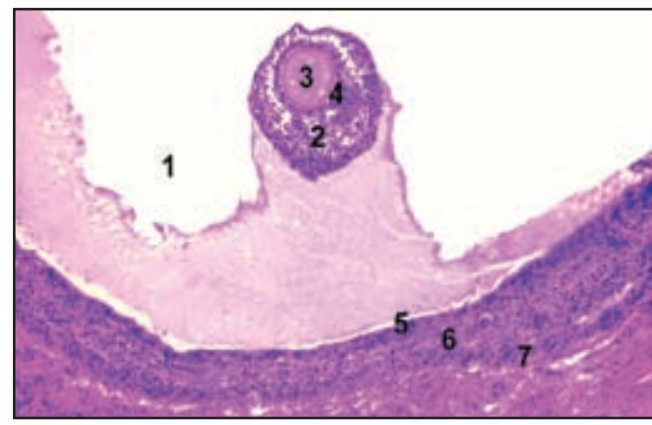

1. Antrum, 2. Cumulus oophorus, 3. Oocyte 4. Zona pellucida, 5. Membrana granulosa 6. Theca interna, 7. Theca externa

The mean length and number of cervical rings were found to be $9.64 \pm 1.19 \mathrm{~cm}$ and $3-5$, respectively. The os externa was rigid and appeared to be rounded with a diameter of $1.74 \pm 0.18 \mathrm{~cm}$. Length and diameter of cervix had a positive correlation with the age and body
Fig. 4. Longitudinal section of cervix. Masson's trichrome method x 400

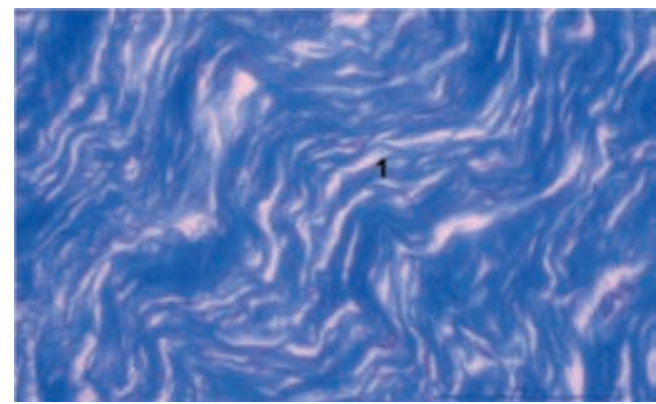

1. Collagen fibres

Fig. 5. Longitudinal section of cervix. Masson's trichrome method x 100

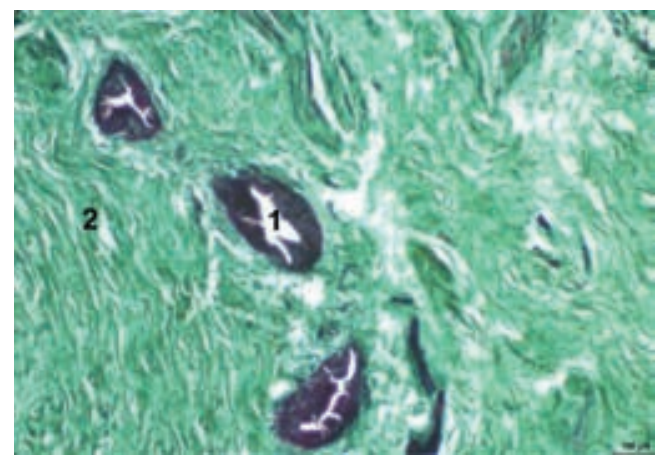

1. Cervical gland, 2. Collagen

Fig. 6. Longitudinal section of cervix. Verhoeff's elastic stain $x \mathbf{4 0 0}$

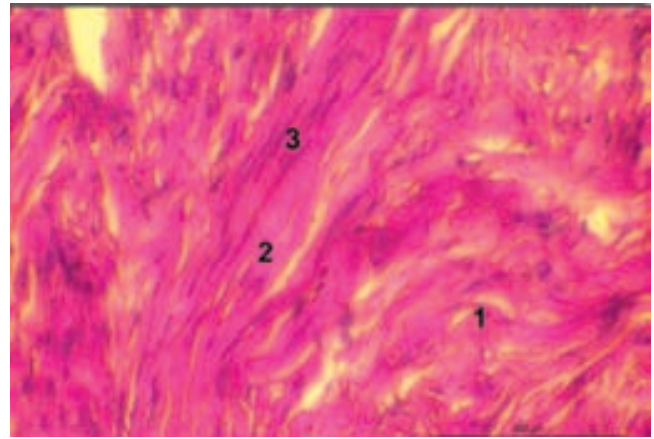

1. Tunica muscularis

2. Collagen fibres

3. Elastic fibres

weight (Khaton et al., 2015). At the external os, the diameter of the cervix was less, while at the uterine end, the diameter was more in control animals. Khaton et al. (2015) observed the maximum length of cervix as $5.64 \pm 0.24 \mathrm{~cm}$ in Local $\times$ Holstein Friesian cross. Similar results 
Fig. 7. Longitudinal section of cervix. PAS Mc Manus method x 400

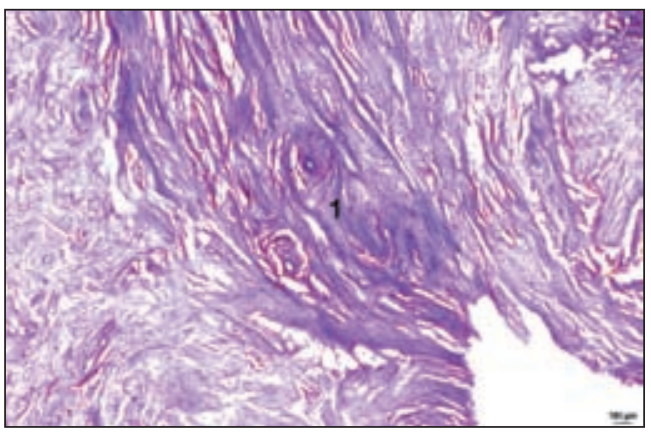

1. Collagen fibres

of Khaton et al. (2015) was also reported by Memon (1996), Kunbhar et al. (2003) and Bello et al. (2012) in bovines, Thari cows and African zebu cattle respectively. According to Varner et al. (1985), cervical diameter had a positive correlation with age and conical shape of the cervix was associated with a lower pregnancy rate in all breeds of cattle. Grossly, cervical rings were thicker and harder compared to the control group. The opening of each cervical ring showed a misalignment instead of a straight line (Fig. 2). Jagir et al. (2009) reported this condition as one of the inherited causes of infertility. Kunbhar et al. (2003) noted that in Thari cows, uterus was the most affected region which included infectious diseases followed by the cervix. The hardness of cervix might be due to lacerations during calving followed by artificial insemination causing infections and fibrosis.

Histologically, in the ovary, cortex and medulla were clearly defined and follicles of different stages including Graafian follicles, regressing corpora lutea and corpus albicans were observed in the cortical region (Fig. 3). This is in agreement with the findings of Fair et al. (1997) and Eurell and Frappier (2006) in bovines. Statistically the cortical thickness showed significant difference when compared to the control animals. In the oviduct, tunica mucosa was composed of lamina epithelialis and lamina propria which blended with the submucosa forming lamina propria-submucosa. The wall of the oviduct was thinner compared to the control animals with thin muscular and serosal coats showing significant difference.
Fig. 8. Longitudinal section of cervix. PAS alcian blue method $x 400$

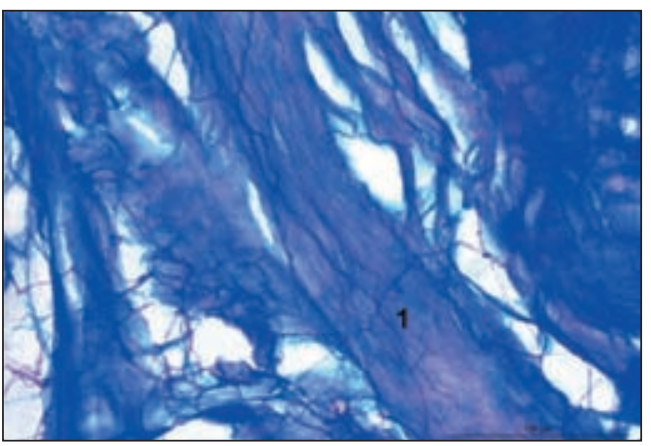

1. Connective tissue

Uterine epithelium was of simple columnar type with oval to elongated basophilic nucleus. In the lamina propria, collagen and elastic fibres were abundant with sparsely distributed reticular fibres. Myometrium was composed of inner circular and outer longitudinal layers. The main difference was noticed in the number of endometrial glands and height of the glandular epithelial cells which was less in affected animals compared to the control group.

In the genitalia with kinked cervix, the main change noticed in the cervical wall was the abundance of fibrous tissue. Mucosa was thrown into numerous folds and was lined by simple columnar epithelium which showed signs of degeneration and desquamation towards their free surface. In the normal cervix, mucosa was highly folded to form primary, secondary and tertiary folds lined by simple columnar epithelium with goblet cells. The submucosal layer was extensively infiltrated by collagen fibres which was confirmed by Masson's trichrome staining (Fig. 4). The stromal layers exhibited only a few glandular structures and in the deep stromal layer, smooth muscle fibres were interspersed with connective tissue (Fig. 5) as reported by Eurell and Frappier (2006) in domestic animals. The tunica muscularis was thin and uneven and was formed of inner circular and outer longitudinal layers. Bundles of dense connective tissue with numerous collagen fibres and a few elastic fibres were infiltrated into tunica muscularis (Fig. 6). This is in accordance with the reports of Breeveld-Dwarkasing (2002) in bovines. In the normal cervix, elastic fibres were more prominent in between the muscle bundles. 
Tunica muscularis was thicker when compared to the control group at one percent level of significance. Morphological alterations of the glandular structures of the cervix negatively influenced the transport of spermatozoa (Adams, 1995) because of the change in secretory products of the glands. Variation in the structural arrangement of collagen network of the cervical connective tissue (Leppert, 1995) formed a major cause of loss of tensile strength of the cervix.

Histochemicallyinthe cervix, presence of carbohydrates, mucin, phosphates and lipids was less when compared to that of control group (Figs. 7 and 8). According to BreeveldDwarkasing (2002), relative concentration of various carbohydrates, glycosaminoglycan and hyaluronic acid in the interstitial matrix may contribute to the regulation of the visco-elastic properties of the connective tissue.

\section{Acknowledgement}

The authors are grateful to Department of Animal Husbandry, Government of Kerala and Kerala Veterinary and Animal Sciences University for granting financial support and for providing necessary facilities needed for carrying out the research.

\section{References}

Adams, N.R. 1995. Detection of the effect phytooestrogens on sheep and cattle. J. Anim. Sci. 73: 1509-1515.

Bello, A., Adamu, Y.A., Umaru, M.A., Garba, S., Abdullahi, A.U., Adamu, M.K., Saidu, B., Ukashatu, S., Hena, S.A. and Mahmuda, A. 2012. Morphometric analysis of the reproductive system of African zebu cattle. J. Zool. 229: 1-6.

Breeveld-Dwarkasing, V.N. 2002. The Bovine Cervix Explored: The Cow as a Model for Studies on Functional Changes in the Cervix Uteri. Utrecht University, Netherlands, 130p.

Eurell, J.A. and Frappier, B.L. 2006. Dellmann's Textbook of Veterinary Histology. $\left(6^{\text {th }}\right.$ Ed.). Blackwell Publishing, USA, 420p.
Fair, T., Hulshof, S.C., Hyttel, P., Greve, T. and Boland, M. 1997. Oocyte ultrastructure in bovine primordial to early tertiary follicles. Anat. Embryol. 195: 327-336.

Jagir, S., Dinesh, D., Mrigank, H. and Ajeet, K. 2009. Incidences of various etiological factors responsible for repeat breeding syndrome in cattle and buffaloes. Internet J. Vet. Med. 6: 1-6.

Kaufman, M.H. and Bard, J.B. 1999.The Anatomical Basis of Mouse Development. Gulf Professional Publishing, Edinburgh, 291p.

Khaton, R., Sarder, M.J.U. and Gofur, M.R. 2015. Biometrical studies of reproductive organs of dairy cows of different genotypes in Bangladesh. Asian J. Anim. Sci. 9: 388-395.

Kunbhar, H.K., Samo, M.U., Memon, A. and Solangi, A.A. 2003. Biometrical studies of reproductive organs of Thari cow. Pakistan J. Biol. Sci. 6: 322-324.

Leppert, P.C. 1995. Anatomy and physiology of cervical ripening. Clin. Obstet. Gynecol. 38: 267-279.

Luna, L.G. 1968. Manual of Histological Staining Methods of the Armed Forces Institute of Pathology. ( $3^{\text {rd }}$ Ed.). Mc Graw Hill Book Company, New York, 258 p.

Memon, M.A. 1996. Bovine Obstetrics: Diagnosis of Pregnancy and Infertility by Rectal Palpation. Department of Veterinary Clinical Science, Washington State University, 68p.

Varner, D.D., Hinrichs, K., Garcia, M.C., Osborne, H.G., Blanchard, T.L. and Kenney, R.M. 1985. A comparison between cervical dimensions of pregnant and non-pregnant Santa Gertrudis and Bos taurus cows. Theriogenology. 24: 109-118. 